\title{
Source of Negative Hydrogen Ions with Hot Cathode
}

\author{
G.I.Kuznetsov, M.A.Batazova \\ Budker Institute of Nuclear Physics, \\ 11 acad.Lavrentyev Ave., \\ Novosibirsk 630090, \\ Russia \\ E-mail: G.I.Kuznetsov@inp.nsk.su
}

\begin{abstract}
In the report an $\mathrm{H}^{-}$-ion source with following parameters is described. Ion energy is up to $30 \mathrm{keV}$, current is up to $5 \mathrm{~mA}$, pulse duration varies from 1 to tens microseconds. $\mathrm{H}$ ions appear in magnetron discharge near a hot cathode surface made of $\mathrm{LaB}_{6}$ or $\mathrm{IrCe}$, which is $6 \mathrm{~mm}$ in diameter. $\mathrm{H}$ ions are extracted through $0.8 \times 6 \mathrm{~mm}$ slot. Input of gas is by means of electromagnetic valve. Ion current depends on discharge current that in turn is defined by cathode temperature, discharge voltage, and hydrogen pressure. Two permanent magnets fixed on iron core generate magnetic field for magnetron discharge. There is a magnetic correction of trajectories of extracted $\mathrm{H}^{-}$ions.

The $\mathrm{H}^{-}$ion source has been used as an injector for tandem accelerator with following proton beam parameters: energy is $1.4 \mathrm{MeV}$, current is $3 \mathrm{~mA}$, and pulse duration is 2 microseconds. Simulation of the ion beam trajectories in source, transportation channel, and tandem accelerator, showed good correlation with experiments on the working installation.
\end{abstract}

\section{INTRODUCTION}

In order to raise the output current of existing in the Institute of Nuclear Physics, Novosibirsk, (INP) synchrotron for therapy of cancer (TRAPP) [1] a stand-by $\mathrm{H}$ source was required. It was decided to mount it on tandem accelerator to have at its exit a proton beam with energy $1.4 \mathrm{MeV}$ [2]. Thus, to have $10^{9}$ protons per pulse at TRAPP output, $10^{10}$ particles during $1 \mathrm{mks}$ was demanded from the source, which means an ion current of about $3 \mathrm{~mA}$. The energy of extraction was chosen $25 \mathrm{kV}$ for better match with tandem accelerator input.

The initial idea was to create $\mathrm{H}^{-}$in the vicinity of a hot cathode surface where electrons have energy high enough to split molecule of hydrogen and at the same time low enough to be captured by hydrogen atom. To create the sheath, a magnetron discharge in transverse electrical and magnetic fields is used

\section{DESIGN}

The scheme of negative ion source is presented in Fig.1. The cathode inserted into discharge chamber is $6 \mathrm{~mm}$ in diameter cathode for industrial accelerator ELV [3]. Transverse magnetic field is induced by means of two permanent magnets put on movable joke that allows one to vary magnetic field in the chamber. Gas hydrogen was injected into the chamber through valve designed and produced in INP [4].

Negative discharge voltage is put on the cathode. High extracting voltage was delivered on electrode with slot respectively.

At first, in the transportation system between ion source and tandem accelerator two electrostatic lenses were used. Considering their aberrations and difficulties with their power supply, they have been changed to magnetic ones. 


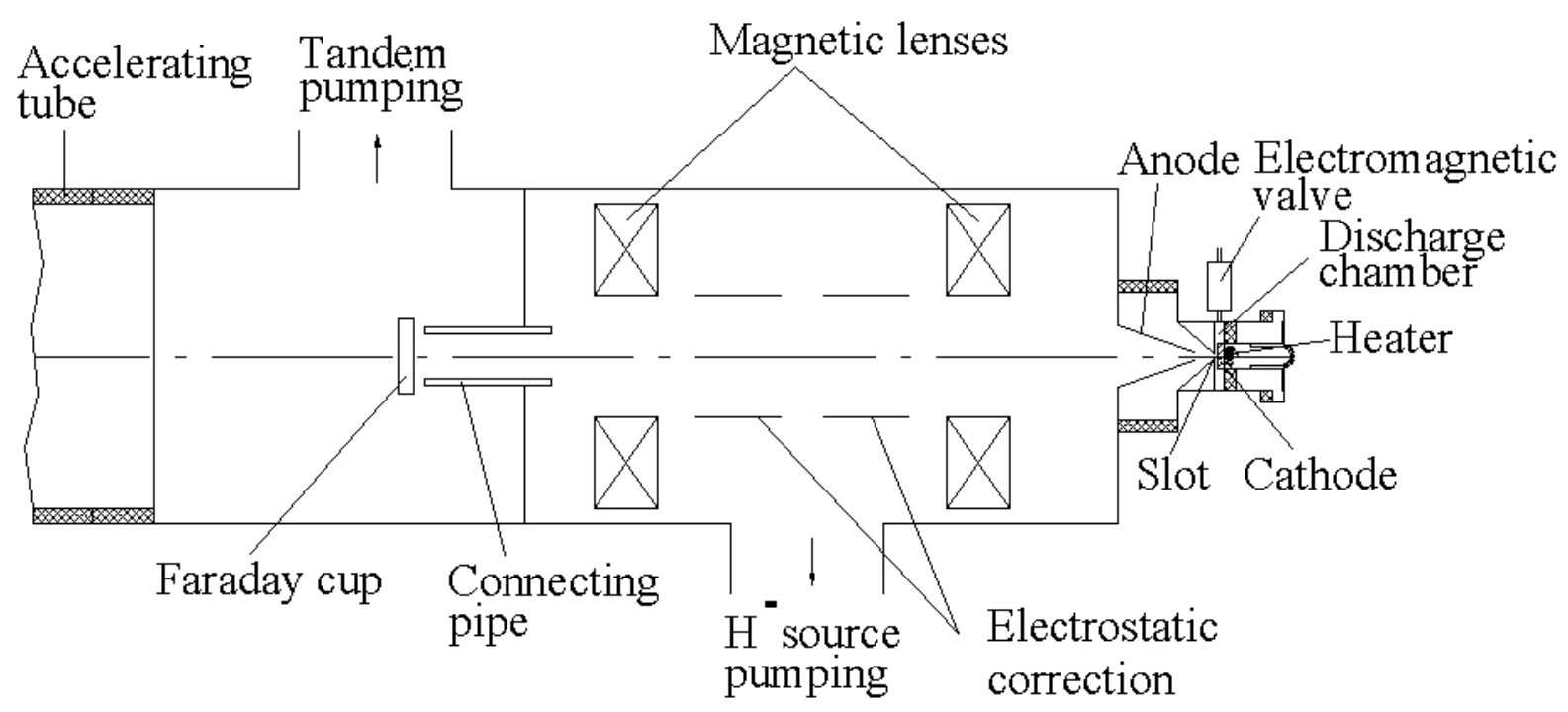

Fig.1. $\mathrm{H}^{-}$source scheme.

In the system there is magnetic correction, which permit to adjust ion beam angle gained due to transverse magnetic field in the extraction area. Between two magnetic lenses of transportation channel, an electrostatic system of parallel shift and deviation of ion trajectories is mounted to aim the beam at the center of recharge tube in the tandem accelerator. At the source output a movable sectioned Faraday cup is situated.

Vacuum tanks of the $\mathrm{H}^{-}$source and tandem accelerator are joined by connecting pipe of a small diameter to separate their volumes. They are pumped by ion pumps NMD0.1 with capacity of $100 \mathrm{l} / \mathrm{sec}$.

\section{SIMULATION}

Extraction of $\mathrm{H}^{-}$is performed from the cathode through the slot of $0.8-0.9 \mathrm{~mm}$ of width and $68 \mathrm{~mm}$ of length. Simulation of ion optics has been made in cylindrical approximation and is presented in Fig.2. Cold cathode-slot gap is $1.5 \mathrm{~mm}$, so taking into account distance drift when heated and sheath thickness, for computing the gap of $1 \mathrm{~mm}$ was chosen. The cathode emission supposed to be non-limited and estimated by ChildLangmuir law, but since space charge is negligible the optics between slot and the anode can be regarded as pure geometrical.

The results of calculation show that $6 \mathrm{~mm}$ cathode can produce up to $5 \mathrm{~mA}$ of $\mathrm{H}$ with angle less than $100 \mathrm{mrad}$ at the anode outlet. Increasing the slot-anode distance, one could reduce this angle, but it leads to rise in deviation in output coordinate of the beam due to transverse magnetic field in discharge chamber. One should be mentioned, that this field was not put into account for simulations.

The rectangular pulse of $\mathrm{H}$ current comes then in transportation system with two magnetic lenses. One of variants of simulation of transportation channel with lenses and tandem accelerator in axial approximation is shown in Fig.3. Adjusting the lens currents we can change input angle of the beam quite smoothly, thus tuning beam coordinates for match with tandem channel and discharge tube. 


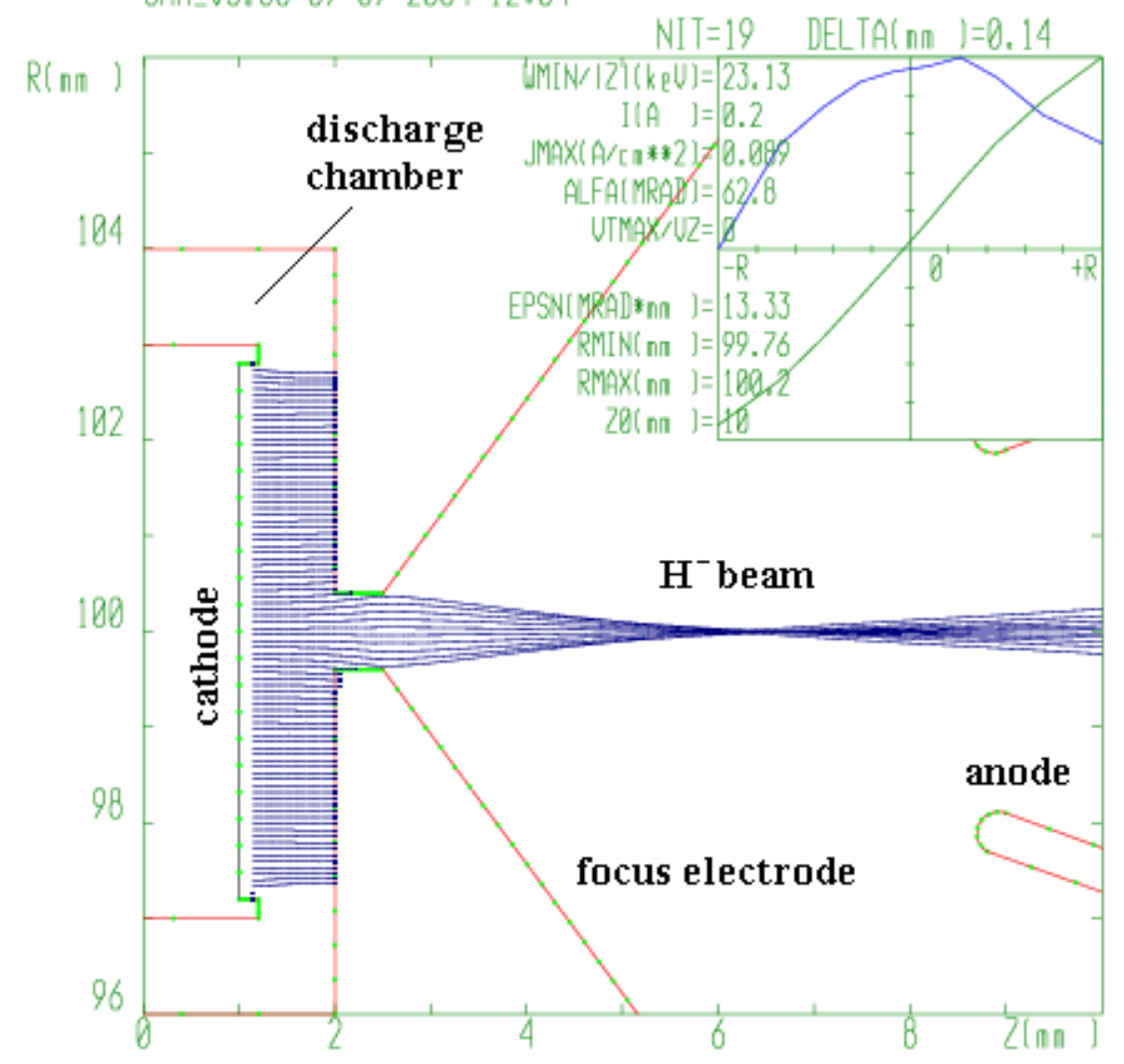

Fig.2. The source optics simulation.

BEAM_U4.7 10-09-2001 10:39

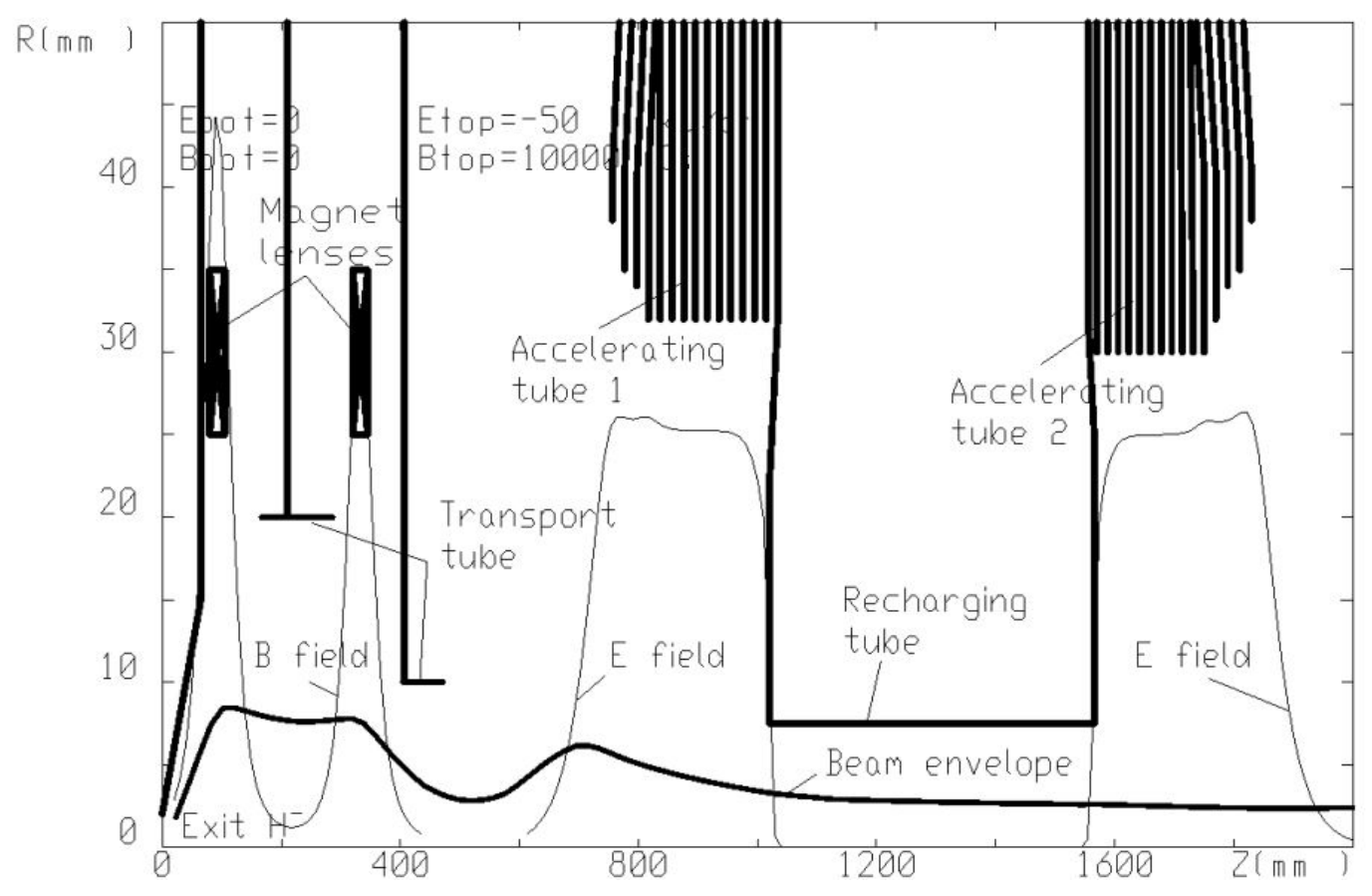

Fig.3. Tandem optics. 


\section{RESULTS}

In Fig. 4 the dependence of $\mathrm{H}$ - current versus discharge one is presented. Two kind of cathode materials have been used for the test, namely, monocrystal of lanthanum hexaboride (face [100]), and Iridium-Cerium alloy. Cold cathode-slot gaps were $1.6 \mathrm{~mm}$ and $1.5 \mathrm{~mm}$ accordingly. The current was measured by Faraday cup at $48 \mathrm{~cm}$ from the cathode surface at the output of the tube that connects the source and tandem accelerator. The beam cross-section was elliptical with axis rate 1:1.5.

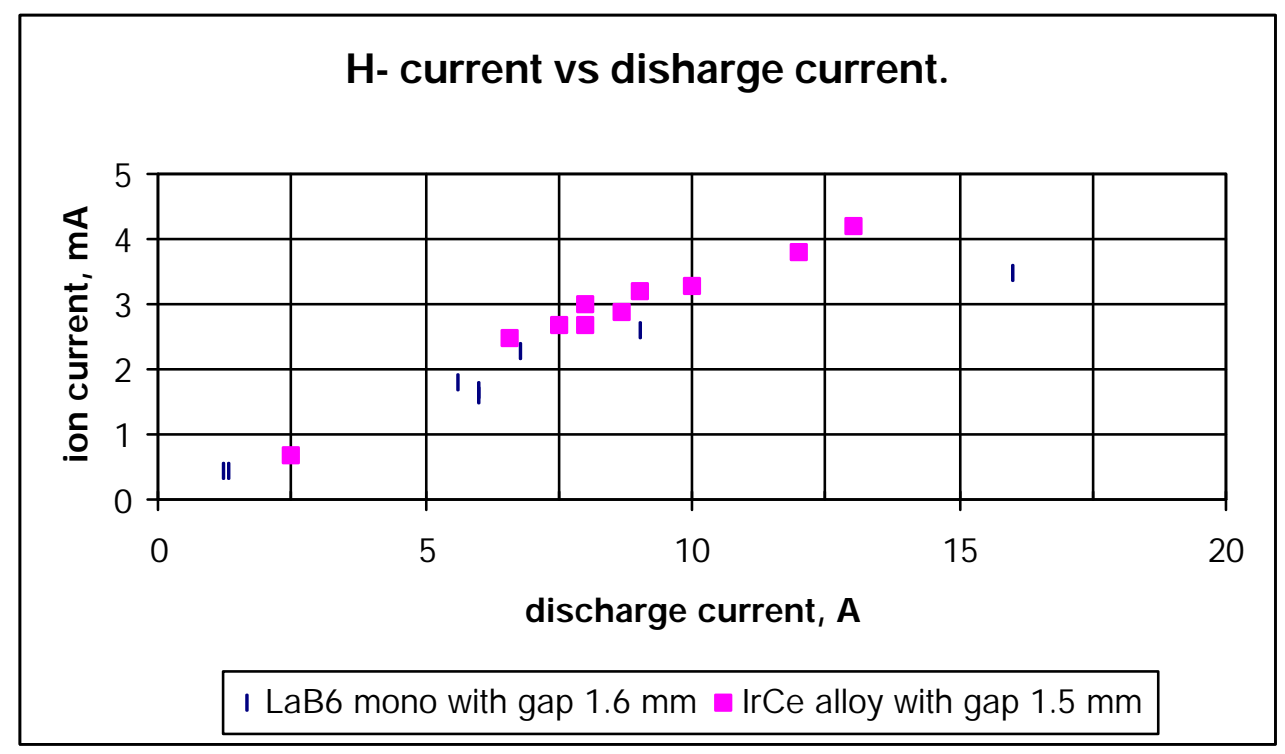

Fig.4. $\mathrm{H}^{-}$current vs discharge current in the source.

The current was measured at the moment when pressure in the discharge chamber attained the value high enough to start the discharge but before the gas filled the transportation channel. If the transportation channel was filled with gas the exit ion current reduced twice. The discharge could burn in the chamber during $2 \mathrm{msec}$ after its ignition, while the current was falling down up to $0.6-0.7$ of its initial value. The time of valve operation is 250450 mks.

The experiments with the source were performed with following parameters:

- duration of discharge pulse

$115 \mathrm{mks}$;

- discharge voltage

$0.11 \mathrm{kV}$;

- magnetic field

$2001500 \mathrm{Gs}$;

- duration of extracting pulse

$16 \mathrm{mks}$;

- extracting pulse voltage

$530 \mathrm{kV}$.

The observed current of $\mathrm{H}^{\top}$ was corresponded to the value computed by $3 / 2$ law for plane diode. The gas amount coming into the discharge chamber during one shot is $13 \cdot 10^{-3} \mathrm{~cm}^{3}$. It is better to have steep front of injected hydrogen in the discharge chamber with more than 3 atmospheres of pressure before gas valve.

In Fig. 5 one can see the proton current of about $2.5 \mathrm{~mA}$ measured at the output of tandem accelerator that was gained from $3 \mathrm{~mA}$ of $\mathrm{H}^{-}$extracted out of the source. The beam diameter is about $8 \mathrm{~mm}$ that is close enough to $6 \mathrm{~mm}$ simulated. 


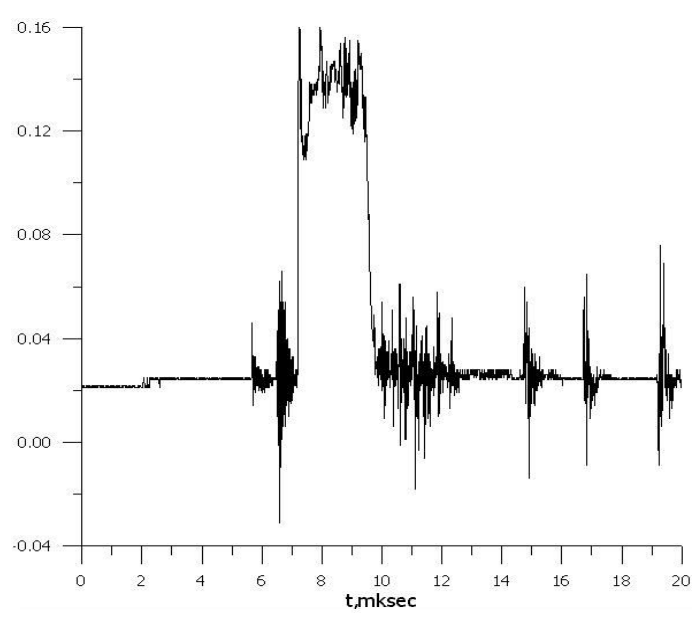

Fig.5. Proton current.

One should be mentioned that $2 \mathrm{~mA}$ of proton current at the tandem output was gained by the very first shot, just after parameters of the tandem and the source itself have been set by computer control.

\section{CONCLUSION}

The source of negative hydrogen ions with hot cathode has been designed, constructed, tested and mounted into tandem accelerator of TRAPP synchrotron. The source allows one to have $35 \mathrm{~mA}$ of $\mathrm{H}^{-}$with energy $25 \mathrm{kV}$ and pulse duration of $0.5 \quad 10$ mks. Its life-time is above 50 hours and limited by interaction of gas hydrogen with lanthanides with hydrides formation. By reducing the source elements we can decrease the amount of gas hydrogen injected to the discharge volume, and extend life-time of the source as well as pumps.

\section{REFERENCES}

1. Balakin V.E., Skrinskiy A.N., et al.

TRAPP-Facility for Proton Therapy of Cancer. EPAC, Rome, 1988, v.2, p.1505.

2. Kuznetsov G.I., Balakin V.E., Batazova M.A., et al.,

Tandem proton acceleratoe as injector for TRAPP, Voprosi Atomnoj Nauki I Tehkniki, 2001, 35, pp15-17, Kharkov.

3. G. Kuznetsov

High temperature cathode for high current density. Nuclear Instruments and Methods in Physics Research, A 340, 1994, pp204-208

4. Derevjankin G.E., Dudnikov V.G., Ghuravlev P.A.

Electromagnetik valve for pulsed gas injection. PTE, 35, 1975, pp.168-169. 